\title{
ПОДХОДЫ К ОЦЕНКЕ РАЗМЕРОВ ПРЕДОХРАНИТЕЛЬНЫХ ЦЕЛИКОВ ВОКРУГ НЕФТЯНЫХ СКВАЖИН НА СОВМЕЩЕННЫХ ТЕРРИТОРИЯХ
}

\author{
А.К. ФЕДОСЕЕВ \\ Горный институт УрО РАН, г. Пермь
}

\begin{abstract}
Аннотация: Оставление охранных целиков вокруг нефтедобывающих скважин при освоении нефтяных залежей на площадях залегания калийных солей является необходимым инструментом обеспечения сохранности водозащитной толщи и ствола скважины, однако, при существующих нормативах это может приводить к существенным экономическим потерям. Целью представленной работы являлась разработка подходов к оценке допустимых размеров охранных целиков вокруг нефтедобывающих скважин, обеспечивающих безопасность ведения горных работ и сохранность герметичности скважин. Геомеханические расчеты основывались на математическом моделировании изменения напряженно-деформированного состояния массива в окрестности скважины вследствие разработки нефтяных залежей и выемки калийных пластов. При анализе учитывались характерные для Верхнекамского месторождения особенности геологического строения и параметры камерной системы разработки вводимых в эксплуатацию участков. Численная реализация осуществлялась в упругопластической постановке методом конечных элементов. По результатам моделирования определены достаточные для безопасного ведения горных работ размеры охранных целиков.
\end{abstract}

Ключевые слова: Напряженно-деформированное состояние; Математическое моделирование; Добыча нефти; Калийные соли; Охранный целик.

Согласно «Правилам промышленной безопасности при освоении месторождений нефти на площадях залегания калийных солей» (ПБ 07-436-02) ширина охранной зоны вокруг глубоких скважин (кустов скважин) определяется в соответствии с размерами радиуса предохранительного целика, рассчитанного в установленном порядке, и должна составлять не менее 500 метров. Наличие в пределах горного отвода нефтедобывающих скважин при оставлении таких охранных целиков может приводить к потере в десятки миллионов тонн запасов калийных солей.

С целью определения допустимых размеров охранных целиков вокруг нефтедобывающих скважин, обеспечивающих безопасность ведения горных работ и сохранность герметичности скважин, проводилось геомеханическое моделирование изменения напряженно-деформированного состояния породного массива для условий совместной разработки нефтяных залежей и выемки запасов калийных солей.

Изменение напряженно-деформированного состояния массива при разработке нефтяных залежей, связанное с извлечением углеводородов и, как следствие, падением пластовых давлений, рассчитывалось на основе положений, сформулированных в [1]. Для оценки максимального воздействия добычи нефти на породный массив снижение пластовых давлений принималось в расчетах по их наибольшим значениям.

По комплексу геомеханических оценок определено, что на территории Верхнекамского месторождения на уровне соляной толщи вклад отработки нефтяной залежи оценивается, приблизительно, в $0.2 \%$ от критических значений показателей для соляных пород. Таким образом, разработка месторождения нефти не оказывает значимого влияния на напряженно-деформированное состояние породного массива, а размер охранных целиков вокруг нефтедобывающих скважин полностью определяется условиями отработки калийных пластов.

Для оценки вклада отработки соляной залежи на изменение напряженнодеформируемого состояния вокруг скважины рассматривался один из вводимых в эксплуатацию участков. Характерные параметры отработки сильвинитовых пластов в его пределах представлены в табл. 1. Принималось, что очистная выемка осуществляется комбайном «Урал-20Р» (ширина камеры 5.5 метра), которая обеспечивает максимальное в данных горно-геологических условиях извлечение калийной руды. 
Параметры системы разработки

\begin{tabular}{|c|c|c|c|c|}
\hline Пласт & $\begin{array}{c}\text { Межосевое } \\
\text { расстояние } \\
(l), \text { м }\end{array}$ & $\begin{array}{c}\text { Ширина ка- } \\
\text { меры }(a), \text { м }\end{array}$ & $\begin{array}{c}\text { Ширина це- } \\
\text { лика }(b), \text { м }\end{array}$ & $\begin{array}{c}\text { Вынимаемая } \\
\text { мощность }(m), \\
\text { м }\end{array}$ \\
\cline { 1 - 4 } КрII & 17.7 & 5.5 & 12.2 & 5.6 \\
\cline { 1 - 4 } КрIII & \multirow{2}{*}{} & 5.5 & 12.2 & 3.1 \\
\hline
\end{tabular}

В соответствии с техническим проектом отработка пласта КрII должна производиться с закладкой очистных камер с коэффициентом заполнения 0.75. По пласту КрIII на границе с охранным целиком планируется создание 200 -метровой зоны смягчения за счет закладки камер также с коэффициентом заполнения 0.75.

Для оценки максимального воздействия отработки калийных пластов на сохранность скважин исследования изменения напряженно-деформированного состояния в области охранного целика осуществлялись на конец процесса сдвижения. Такой подход является обоснованным, поскольку вследствие осложнений геологического строения соляной толщи, выраженного, например, в повышенном содержании нерастворимого остатка, фактическая степень нагружения междукамерных целиков может превысить расчетную [2], что приведет к ускоренным деформациям подработанного массива.

Математическое моделирование напряженно-деформированного состояния подработанного массива проводилось в соответствии с требованиями п. 3.52.3. «Указаний по защите рудников от затопления и охране подрабатываемых объектов в условиях ВКМКС» [3]. Базовые положения методики геомеханических расчетов изложены в «Методических рекомендациях (раздел 5) к «Указаниям...» [4]. Для анализа деформирования подработанного массива во времени использовался реологический подход, основанный на математическом описании фактических и/или прогнозных графиков нарастания оседаний земной поверхности, и реализованный на основе модификации известного в практике реологического анализа метода переменных модулей упругости $[5,6]$. В качестве определяющего уравнения нелинейной связи напряжений и деформаций использовалась идеальная упругопластическая модель. Паспорт прочности соляных пород описывался параболической огибающей кругов Мора [7]. Численная реализация математического моделирования осуществлялась методом конечных элементов в двухмерной постановке, решение которой обеспечивает получение определенного «запаса» в оценках разрушения породного массива в окрестности охранных целиков вокруг скважин.

Вертикальные смещения земной поверхности вследствие отработки сильвинитовых пластов на границе охранного целика имеют канонический вид и не представляют особого интереса. Непосредственно в окрестности скважины с уменьшением радиуса охранного целика с 500 до 250 метров оседания увеличиваются с 0 до 15 см. В соответствии с результатами моделирования в интервале соляной толщи возможно образование области сдвиговой трещиноватости, которая локализуется в узкой зоне краевой части выработанного пространства и по вертикали не распространяется выше пласта Б (рис. 1).

Формирование данной области разрушения не зависит от радиуса охранного целика, а полностью определяется принятыми параметрами отработки сильвинитовых пластов. Область разрушения породного массива вследствие отрыва формируется непосредственно в верхней части геологического разреза в окрестности нефтедобывающей скважины и в явном виде проявляется при радиусе охранного целика 250 метров (рис. 1 в).

Изменение горизонтальных деформаций растяжения в пределах охранного целика при различных его размерах носит похожий характер (рис. 2). Зона растяжения в интервале соляной толщи с деформациями, не превышающими нижние оценки предельных для соля- 
ных пород величин (0.1\%), обусловлена только горными работами и не зависит от размеров охранного целика вокруг нефтяных скважин. Вторая область растяжения формируется в верхней части разреза и охватывает в плане всю площадь охранного целика. С уменьшением его радиуса отмечается увеличение горизонтальных деформаций растяжения в окрестности нефтедобывающей скважины и развитие зоны растяжения вниз по разрезу. При радиусе охранного целика 250 метров (рис. 2 в) деформации растяжения превышают $0.2 \%$ и распространяются практически до кровли СМТ.

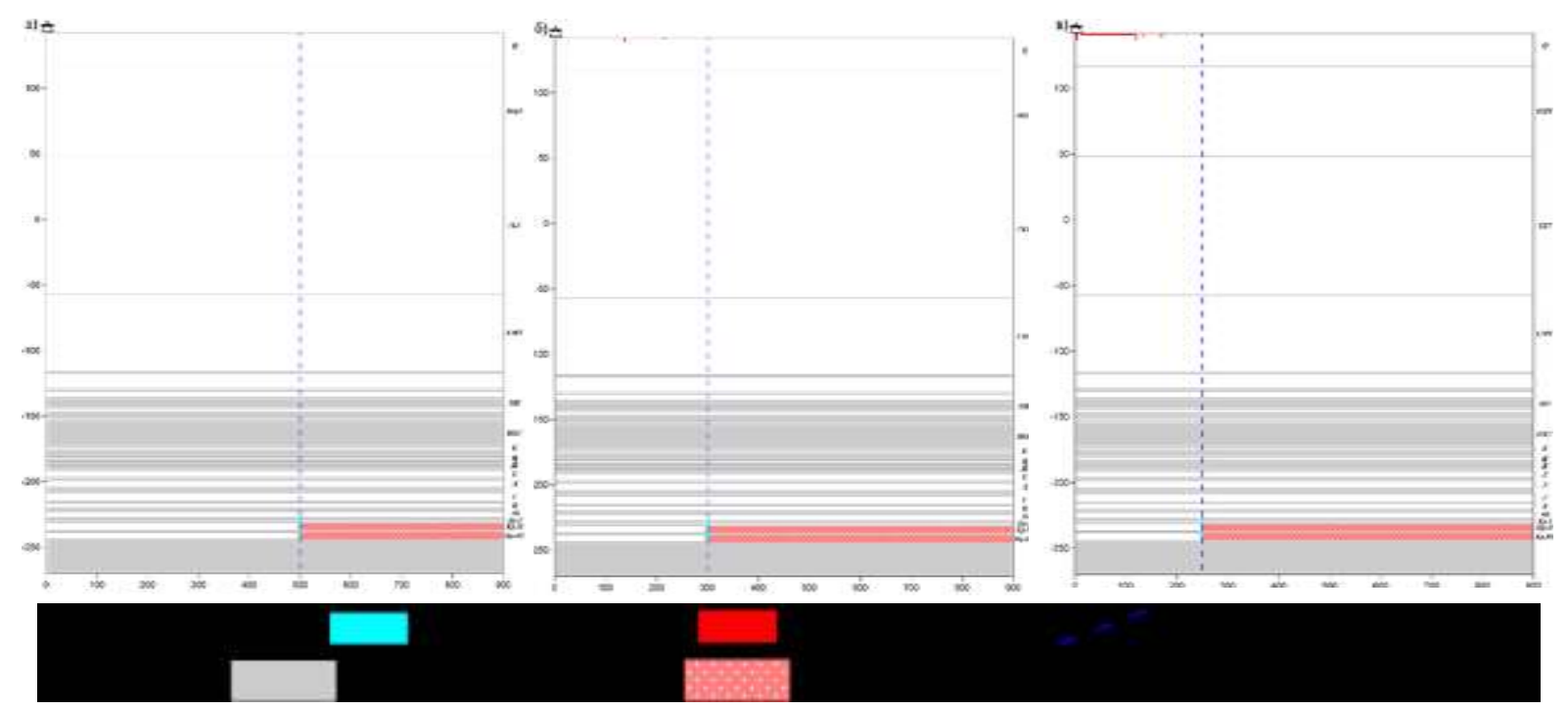

Рис. 1. Характер техногенного нарушения вследствие отработки калийных пластов при радиусе охранного целика: 500 (а), 300 (б) и 250 (в) метров

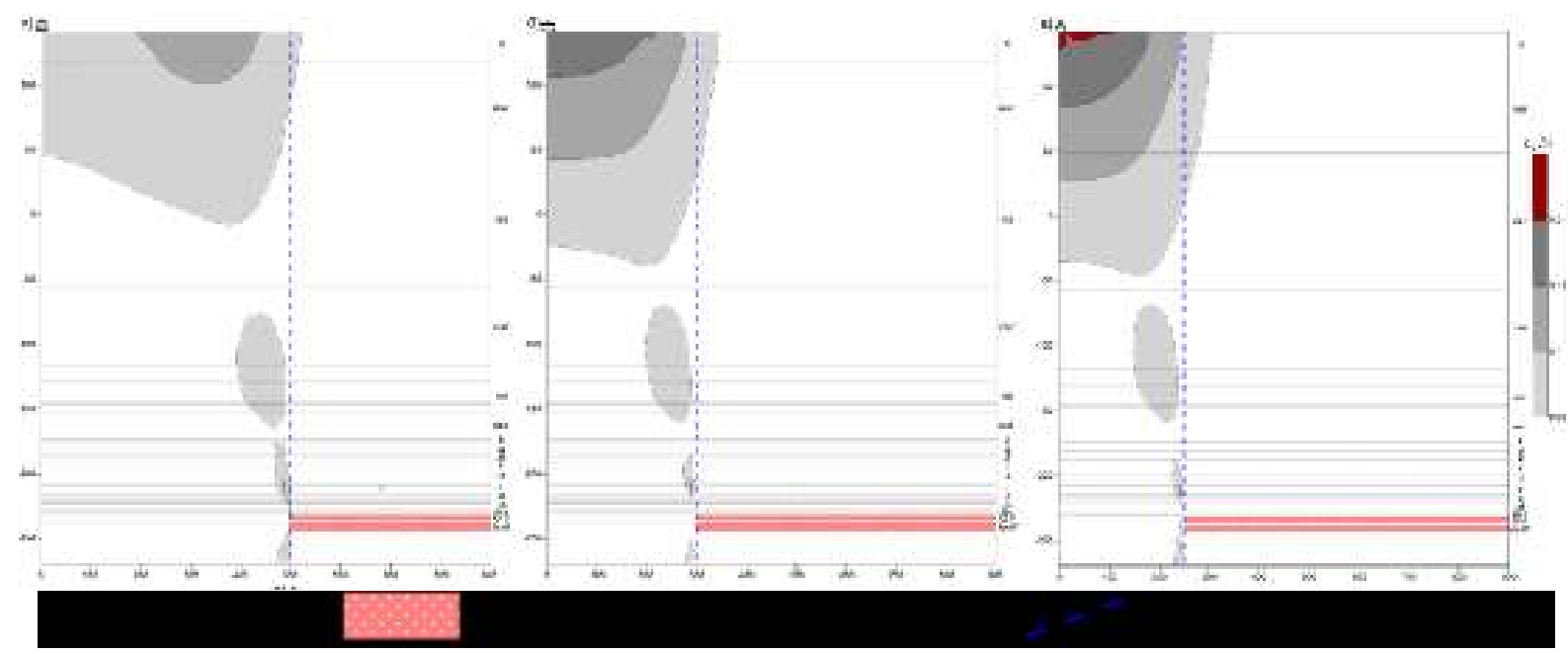

Рис. 2. Распределение горизонтальных деформаций растяжения в подработанном массиве при радиусе охранного целика: 500 (а), 300 (б) и 250 (в) метров

Следует особо подчеркнуть, что полученные результаты справедливы только для принятых горнотехнических условий отработки сильвинитовых пластов КрІІ и КрIII. В качестве иллюстрации показан вариант их очистной выемки без закладки пласта КрII и в отсутствие зоны смягчения по пласту КрIII (рис. 3). В этом случае уменьшение радиуса охранного целика даже до 300 метров обусловливает возникновение обширной зоны разрушения породного массива вследствие отрыва (рис. 3 б) и интенсификацию деформаций растяжения (рис. 3 a), охватывающих всю подработанную толщу в непосредственной окрестности скважины. По-видимому, в этих условиях уменьшение размеров охранных целиков вокруг нефтедобывающих скважин является проблематичным. 
Таким образом, геомеханические исследования показали, что при принятых параметрах разработки запасов сильвинита радиус охранного целика вокруг нефтедобывающих скважин может быть уменьшен до 300 метров. При этом обеспечивается безопасность горных работ, долговременная устойчивость водозащитной толщи и сохранность герметичности нефтедобывающих скважин.
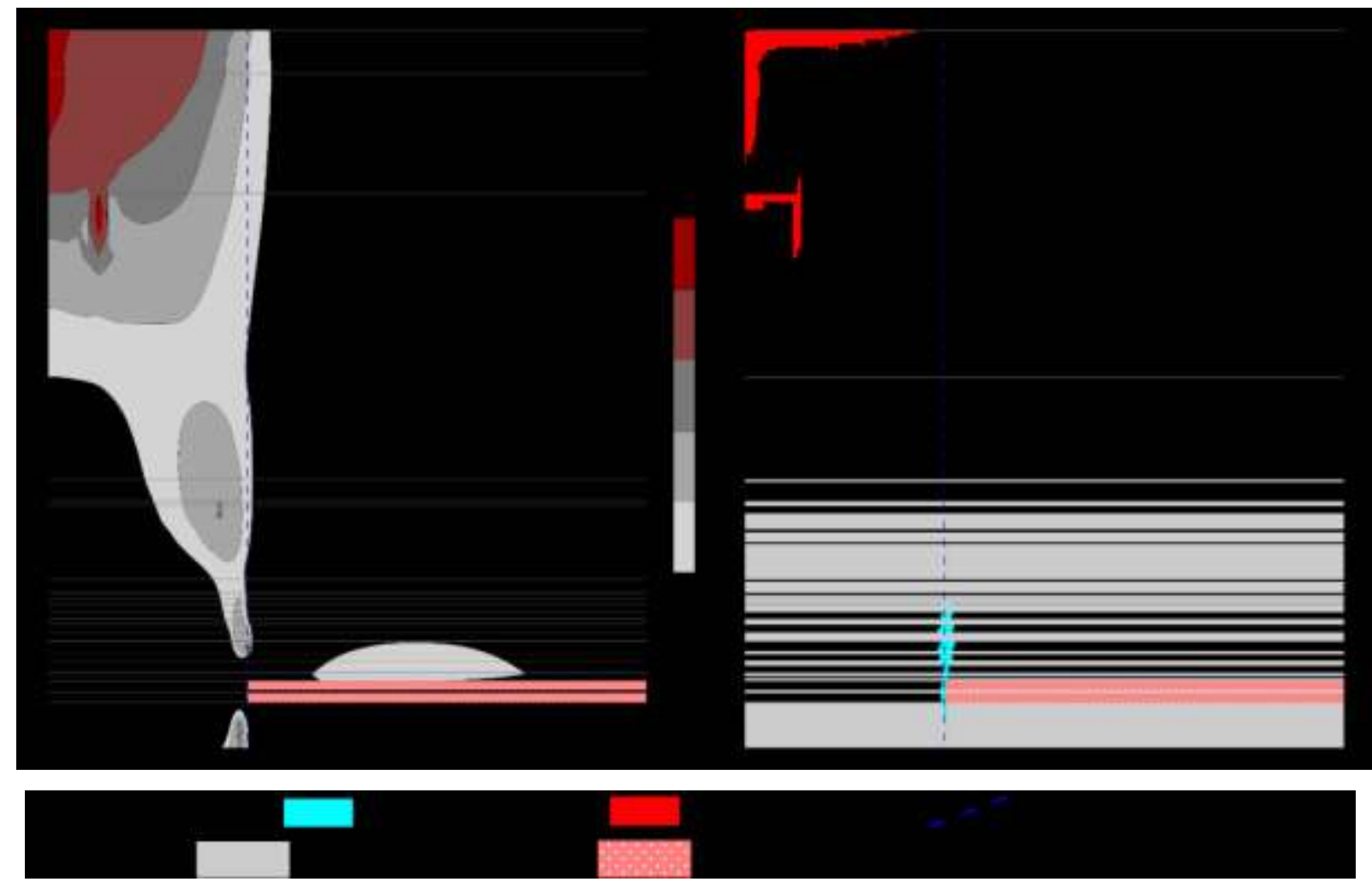

Рис. 3. Распределение горизонтальных деформаций растяжения (а) и техногенного нарушения (б) в подработанном массиве без закладки камер по пласту КрII и зоны смягчения в пласте КрIII при радиусе охранного целика 300 метров

\section{БИБЛИОГРАФИЧЕСКИЙ СПИСОК}

1 Федосеев А.К. Принципы и подходы к оценке воздействия разработки залежей нефти на состояние недр // Стратегия и процессы освоения георесурсов: материалы науч. сес. ГИ УрО РАН по результатам НИР в 2004 г. - Пермь, 2005. - С. 189-191.

2 Обеспечение безопасности освоения балансовых запасов сильвинита на руднике ООО «ЕВРОХИМ УСОЛЬСКИЙ КАЛИЙНЫЙ КОМБИНАТ»: Отчет о НИР по договору № 210-0152508 с ООО «ЕврохимУКК» / ГИ УрО РАН; рук. А.А. Барях; отв. исполн. С.Ю. Лобанов. - Пермь, 2018. - 46 с.

3 Указания по защите рудников от затопления и охране подрабатываемых объектов на Верхнекамском месторождении калийно-магниевых солей: утв. ПАО «Уралкалий», ЗАО «Верхнекамская калийная компания», ООО «ЕвроХим-Усольский Калийный комбинат». - введ. в действие 30.03 .2017 в ред. 2014 г. Пермь; Березники, 2014. - 130 с.

4 Методические рекомендации к «Указаниям по защите рудников от затопления и охране подрабатываемых объектов в условиях Верхнекамского месторождения калийных солей»: введ. в действие с 30.03.2017 г., в ред. 2014 г. - Пермь; Березники, 2014. -

5 Амусин, Б.З., Линьков А.М. Об использовании переменных модулей для решения одного класса задач линейно-наследственной ползучести // Механика твердого тела. - 1974. - № 6. - С. 162-166.

6 Baryakh A.A., Samodelkina N.A Rheological analysis of geomechanical processes // Journal of Mining Science. - 2005. - V. 41, № 6. - P. 522-530. DOI: 10.1007/s10913-006-0015-x.

7 Кузнецов Г.Н. Механические свойства горных пород. - М.: Углетехиздат. - 1947. - 180 с. 